\title{
O ângulo funcional mastigatório de Planas (AFMP) e a finalização ortodôntica
}

\section{Planas Functional Masticatory Angle and Orthodontic Treatment Finishing}

\author{
LEANDRO BIELLI Ross \\ Mestre em Ortodontia pelo Centro Universitário de Araraquara - UNIARA \\ Carolina Cordeiro Marchese \\ Graduada pela Faculdade de Odontologia de Lins - UNIMEP \\ Marco Polo Marchese \\ Professor da Faculdade de Odontologia de Lins - UNIMEP \\ Dario Fernandes Lopes Neto \\ Mestre em Ortodontia pelo Centro Universitário de Araraquara - UNIARA \\ NADIA LUNARDI \\ Professora de Ortodontia do Centro Universitário de Araraquara - UNIARA
}

\begin{abstract}
RESUMO
As chaves de oclusão devem estar presentes em uma oclusão ideal, portanto na correta finalização ortodôntica. Esses parâmetros são estáticos, porém a oclusão também deve ser analisada dinamicamente. Objetivo: a proposta deste trabalho é ilustrar, por meio de três casos clínicos, as chaves estáticas e dinâmicas e os ajustes que são preconizados para a obtenção do ângulo funcional mastigatório de Planas (AFMP) iguais. Relato de caso: foram relatados três casos clínicos com diferentes graus de dificuldade de tratamento: um classe I com diastemas e giroversões; classe I com uma sobremordida acentuada; e classe III, subdivisão direita com mordida aberta anterior. Os casos foram detalhados quanto à finalização, demonstrando a oclusão estática e ajustes para obtenção de adequada oclusão dinâmica. Conclusão: ajustes oclusais, após tratamento ortodôntico, melhoram a estabilidade oclusal e funcional, proporcionando um equilíbrio dentário e permitindo ao paciente uma mastigação bilateral.
\end{abstract}

Palavras-chave: ortodontia; oclusão dentária balanceada; ajuste oclusal; oclusão dentária.

\begin{abstract}
The occlusion keys must be present in an ideal occlusion, so on the correct orthodontic finishing. These are static parameters, but the occlusion should also be dynamically analyzed. Purpose: The purpose of this study is to illustrate, through three clinical reports, the static and dynamic keys and settings that are recommended to obtain equal Planas Functional Masticatory Angle (PFMA). Case Report: Three reported clinical cases with different difficulty degrees of treatment: the first is a Class I malocclusion with spacing and rotations; the second one is another Class I malocclusion with a pronounced overbite; and the third is a Class III right subdivision with anterior open bite. The cases were detailed as to the finishing, demonstrating static occlusion and adjustments to achieve adequate dynamic occlusion. Conclusion: occlusal adjustments after orthodontic treatment improve the functional and occlusion stability, providing dental balance and allowing bilateral chewing.
\end{abstract}

Keywords: orthodontics; balanced dental occlusion; occlusal adjustment; dental occlusion. 


\section{INTRODUÇÃO}

Um dos grandes desafios da ortodontia está na manutenção da estabilidade da oclusão e harmonia facial obtidas ao final de um tratamento, principalmente por ela ser independente da técnica e possuir uma ação multifatorial. ${ }^{1}$ Por muitas décadas, a finalização do tratamento baseava-se em um padrão oclusal estático, no qual o equilíbrio oclusal era considerado fator de estabilização dentária e parte importante na busca pela excelência. Muitos autores definiram parâmetros ideais a serem obtidos ao final do tratamento ortodôntico $2,3,4,5$.

No entanto, o sistema estomatognático é um conjunto interligado de estruturas responsáveis por muitas funções vitais, como a mastigação, respiração, deglutição, sucção e fala. O equilíbrio destas funções é imprescindível para harmonia, saúde e estabilidade de todo o sistema. Um desequilíbrio qualquer destas estruturas pode levar ao desequilíbrio do sistema como um todo, podendo, certamente, desencadear recidivas ou mesmo instalar desordens temporomandibulares, dentre outros problemas. ${ }^{6,7}$ Neste contexto, Planas, ${ }^{8}$ após anos de observação clínica, destacou a importância do equilíbrio nas lateralidades direita e esquerda para a obtenção de equilíbrio e estabilidade na oclusão. O autor definiu como ângulo funcional mastigatório de Planas (AFMP) o ângulo formado pelo aumento da dimensão vertical direita e esquerda e o plano horizontal durante a lateralidade. Segundo o autor, se houver uma diferença entre os ângulos de desoclusão (AFMP), o indivíduo permanecerá com ou desenvolverá uma mastigação unilateral, comprometendo, assim, a estabilidade da correção da má oclusão no longo prazo.

Portanto, parece pertinente salientar que, para a obtenção do equilíbrio do sistema estomatognático e consequente estabilidade do tratamento ortodôntico, é indispensável a análise das oclusões estática e dinâmica, nas quais deverão ser verificados os padrões de desoclusão (lateralidade, protrusão) sem contatos deletérios, ângulos de desoclusão diferentes (AFMP) e presença de mastigação unilateral. Este trabalho tem como objetivo ilustrar as chaves estáticas e dinâmicas e os ajustes preconizados para a obtenção de AFMPs equilibrados.

\section{Caso Clínico 1}

Paciente do sexo feminino, de 16 anos, mesofacial, apresentando maloclusão de classe I de Angle, ausência de contato entre o elemento 13 e seus antagonistas, caracterizando infraoclusão deste elemento, presença de diastemas no arco inferior, giroversões dos elementos 14, 15, 24, 25, 34 e 35 , presença de sobremordida e desnível acentuado entre os incisivos centrais e laterais superiores (Figura 1).

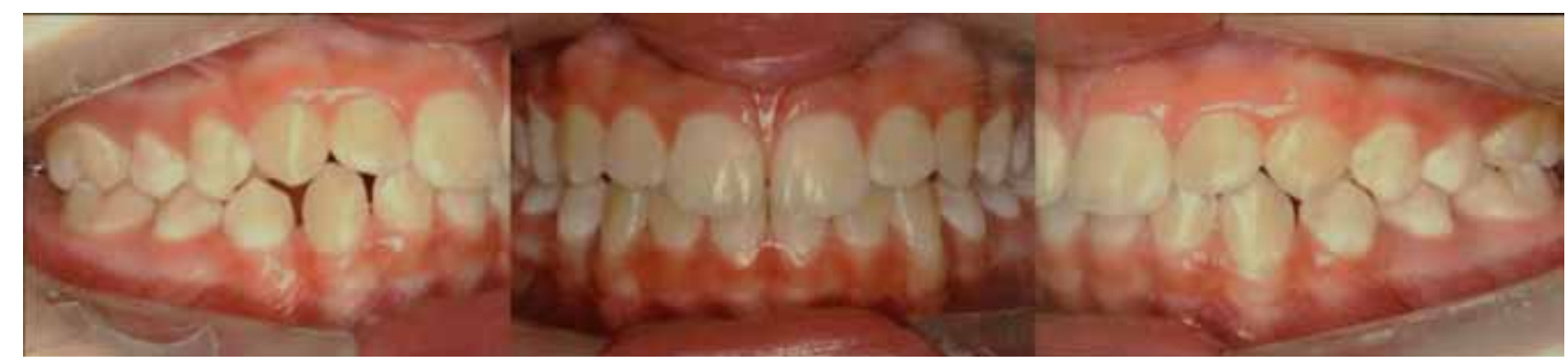

Figura 1 - Fotos intrabucais iniciais: nota-se a maloclusão de classe I com sobremordida 


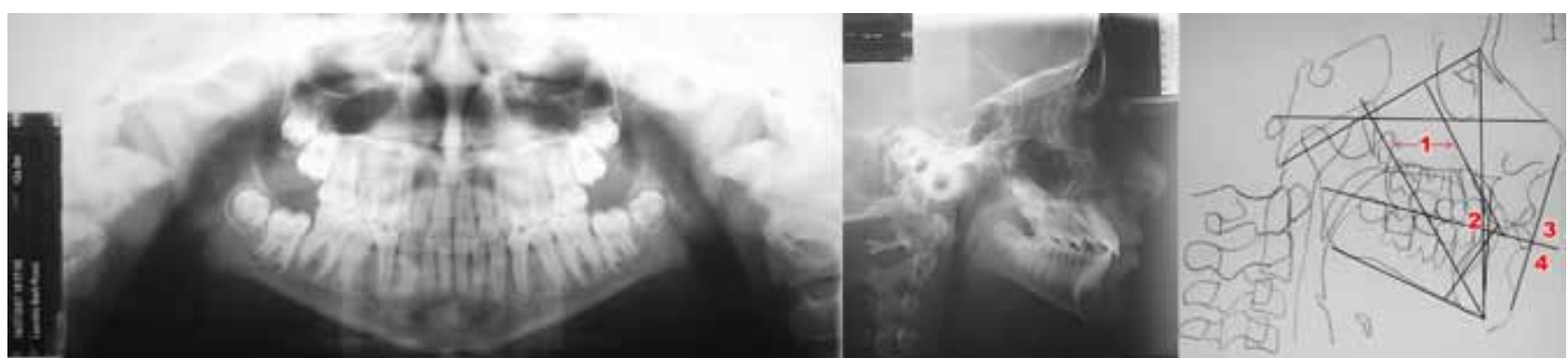

Figura 2 - Radiografia panorâmica, telerradiografia e traçado cefalométrico inicial

Ao analisar o traçado cefalométrico inicial, nota-se o paralelismo do eixo do incisivo superior ao eixo facial (Pt-Gn) e a extrusão dos incisivos inferiores em relação ao plano oclusal verdadeiro, evidenciando a necessidade da intrusão destes para a correção da curva Spee e da sobremordida, um ângulo interincisivo menor que a norma recomendada para o tipo facial e um perfil mole harmônico (Figura 2).

A paciente foi submetida à mecânica ortodôntica de nivelamento da Cursa Spee por meio da intrusão dos incisivos inferiores e correção de sua angulação com o uso do arco base de Ricketts, e, por meio dos arcos de alinhamento e nivelamento, foram corrigidas as giroversões, diastemas e desnivelamentos, finalizando, assim, a correção ortodôntica. Removido o aparelho corretivo, foi instalado um arco de Hawley para a contenção do arco superior e, colada nos dentes inferiores, uma barra de canino a canino com dobras para facilitar a higienização com fio dental. Após noventa dias, foram requisitados novos exames fotográficos e radiográficos (Figuras 3 e 4).

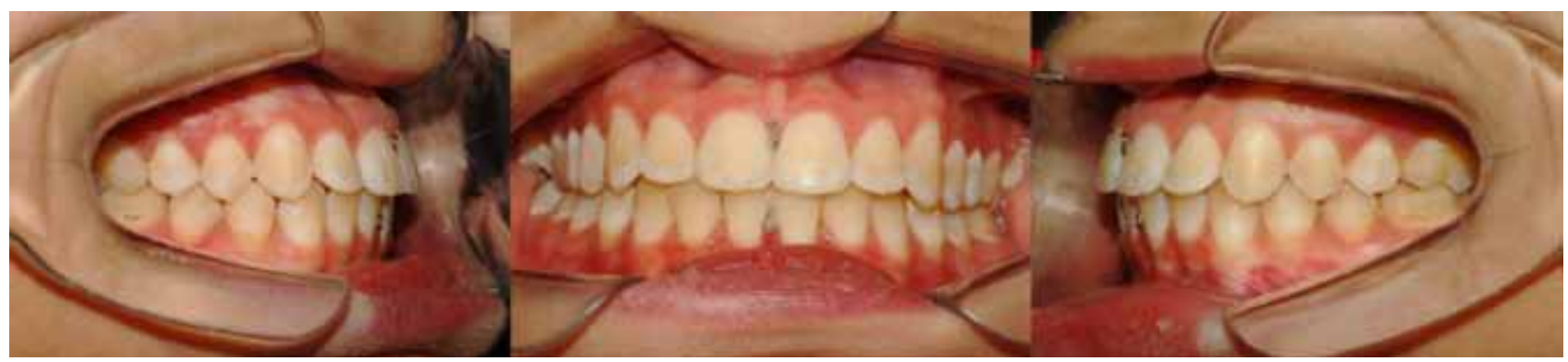

Figura 3 - Fotos intrabucais noventa dias após a correção ortodôntica e remoção do aparelho fixo

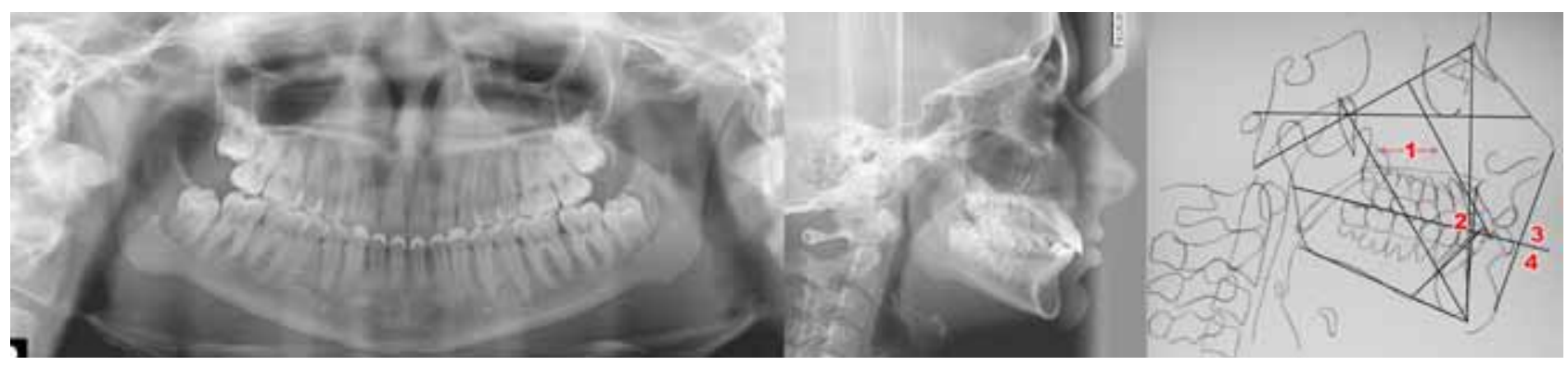

Figura 4 - Radiografia panorâmica, telerradiografia e traçado cefalométrico final 
Nota-se na radiografia panorâmica final a integridade óssea e das raízes, assim como o paralelismo entre elas. O traçado cefalométrico final mostra que todas as mudanças propostas foram solucionadas: a correção da curva Spee por meio da intrusão dos incisivos inferiores, a correção da angulação dos incisivos inferiores, a manutenção do paralelismo entre o eixo dos incisivos superiores e o eixo facial e a manutenção do perfil mole harmônico (Figura 4).
Checadas as chaves de oclusão segundo Andrews e Ricketts, seguiu-se análise dinâmica desta, por meio dos movimentos excursivos de protrusão e lateralidade direita e esquerda. Eliminados os contatos deletérios do lado de trabalho e não trabalho por meio de ajuste oclusal, as desoclusões de lateralidade foram baseadas em desoclusão de guia canino, sem interferência do lado de não trabalho (Figura 5).

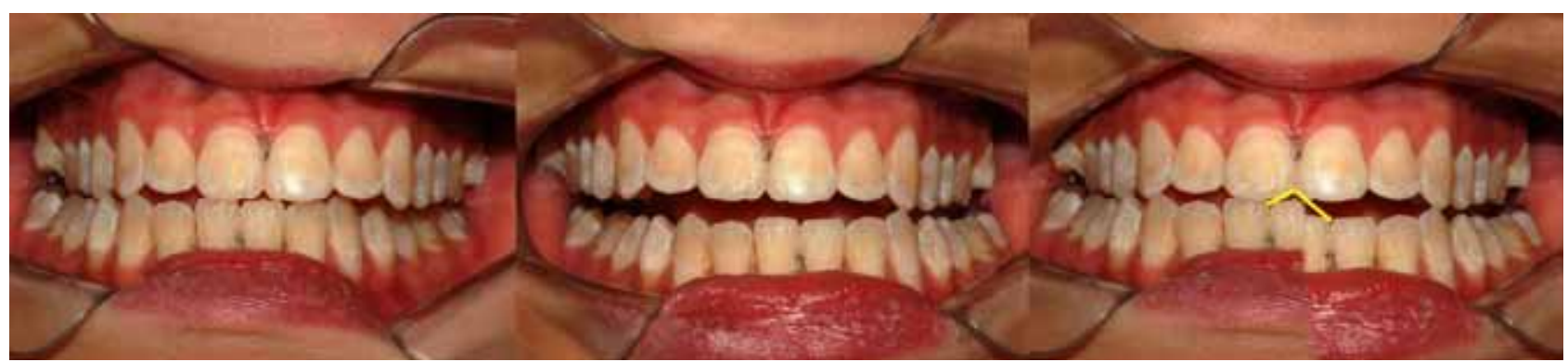

Figura 5 - Lateralidade direita e esquerda, desoclusão pelos caninos sem contato do lado de não trabalho e edição das fotos anteriores evidenciando as diferenças entre a separação dos dentes de ambos os lados e representação gráfica da diferença dos AFMP

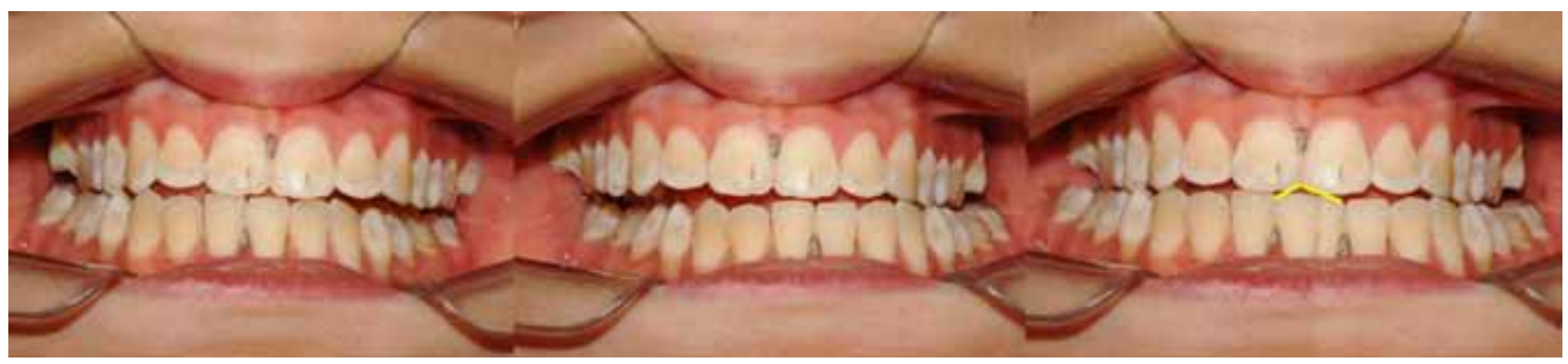

Figura 6 - AFMP equilibrados e edição das fotos anteriores evidenciando o equilíbrio dos AFMPs

Verificada a diferença entre os ângulos funcionais mastigatórios de Planas (Figura 5), um novo ajuste oclusal foi realizado na guia de desoclusão, realizada pelo canino esquerdo para equilibrar-se com o ângulo da guia do canino direito (Figura 6).

\section{Caso clínico 2}

Paciente do sexo masculino, 13 anos, mesofacial, apresentando maloclusão de classe I de Angle, presença do elemento 63, vestíbulo-versões dos elementos 12 e 22 , apinhamento e giroversão dos elementos $33 \mathrm{e}$ 43 , presença de sobremordida acentuada com desnível entre os incisivos centrais e laterais superiores (Figura 7).

Ao analisar o traçado cefalométrico inicial, nota-se a convergência do eixo do incisivo superior ao eixo facial (Pt-Gn) e a extrusão dos incisivos inferiores em relação ao plano oclusal verdadeiro, evidenciando a necessidade da intrusão destes para a correção da curva Spee. Também será necessário corrigir o torque e intruir os incisivos superiores para a correção 


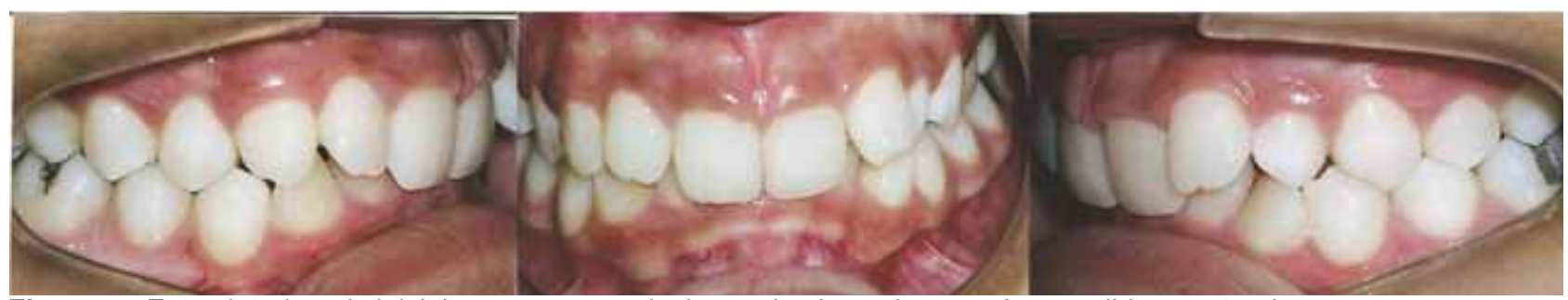

Figura 7 - Fotos intrabucais iniciais: nota-se a maloclusão de classe I com sobremordida acentuada
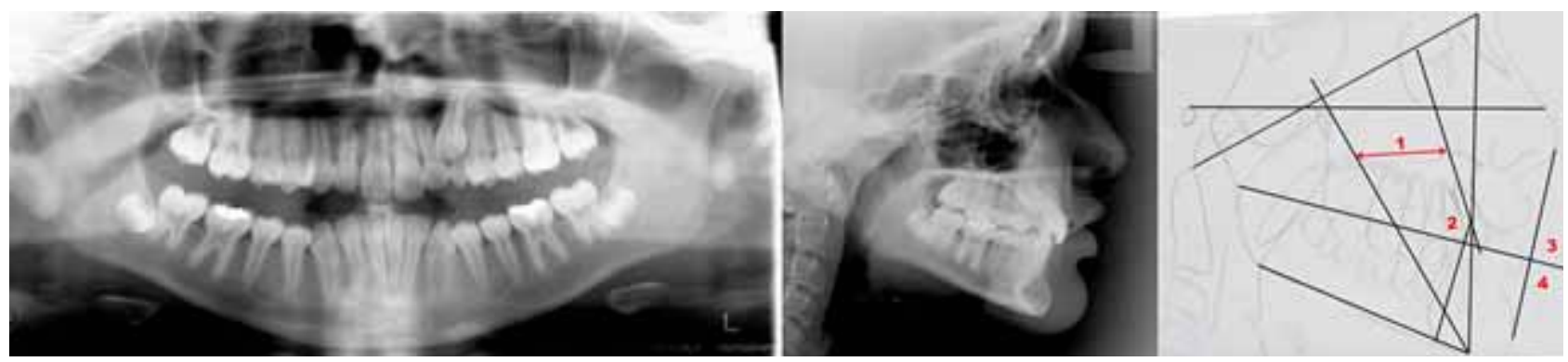

Figura 8 - Radiografia panorâmica, telerradiografia e traçado cefalométrico inicial

da sobremordida, com um ângulo interincisivo aumentado em virtude de uma verticalização dos incisivos, maior que a norma recomendada para o tipo facial e um perfil mole harmônico (Figura 8).

O paciente foi submetido a mecânica ortodôntica de intrusão dos incisivos superiores, assim como o nivelamento da curva Spee por meio da intrusão dos incisivos inferiores com correção de suas angulações e posicionamento anteroposterior pelo uso do arco base de Ricketts, solucionando, assim, a mordida profunda. Por meio de arcos de alinhamento e nivelamento, foram corrigidas as giroversões, apinhaentos e desnivelamentos, finalizando, assim, a correção ortodôntica. Removido o aparelho corretivo, foi instalado um arco de Hawley para a contenção do arco superior. Nos dentes inferiores foi colada uma barra de canino a canino com dobras para facilitar a higienização (Figuras 9 e 10).

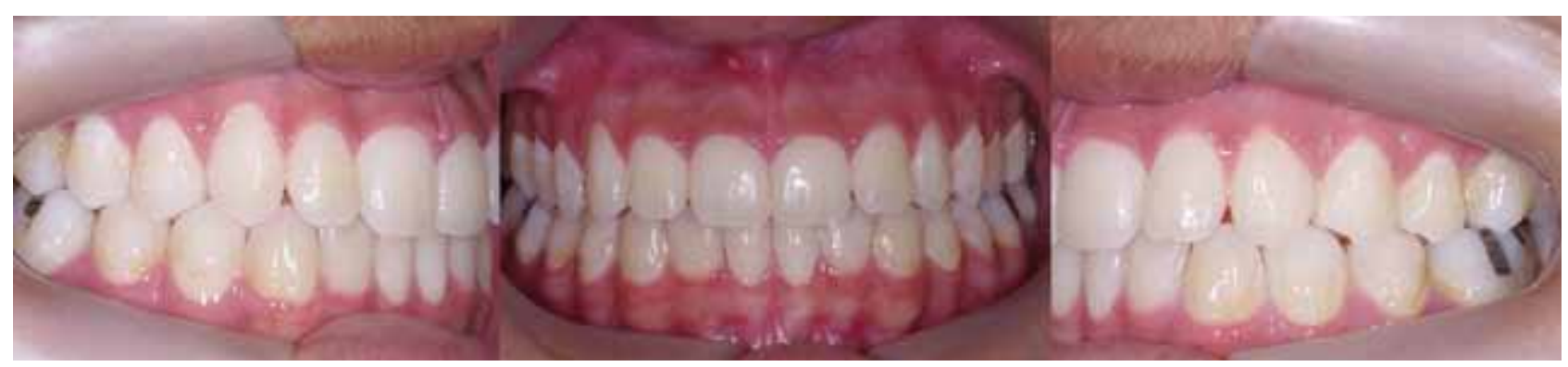

Figura 9 - Fotos intrabucais após a correção ortodôntica e remoção do aparelho fixo
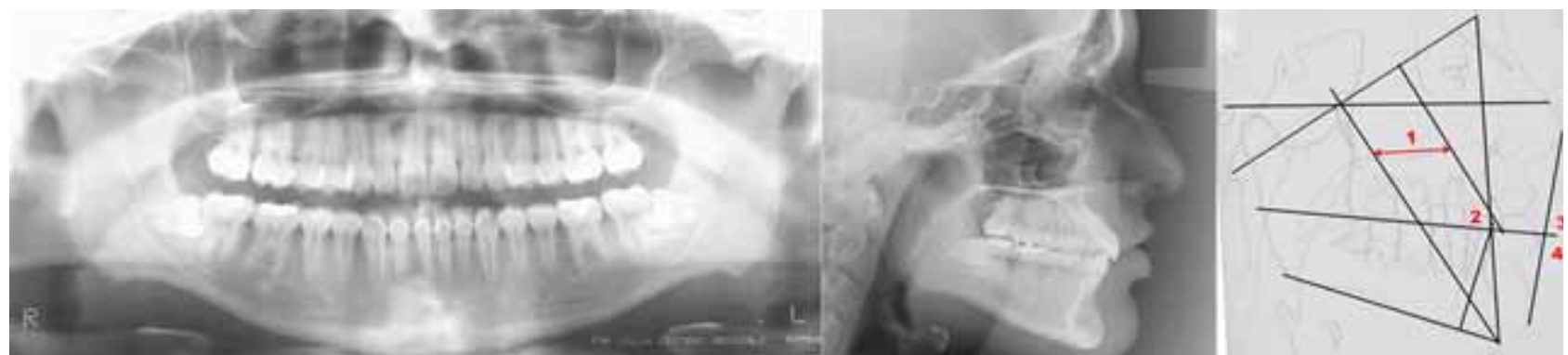

Figura 10 - Radiografia panorâmica, telerradiografia e traçado cefalométrico final 
Nota-se na radiografia panorâmica final a integridade óssea e das raízes assim como o paralelismo entre elas. O traçado cefalométrico final mostra que todas as mudanças propostas foram solucionadas: a correção da curva Spee por meio da intrusão dos incisivos inferiores e superiores, a correção da angulação dos incisivos inferiores e dos superiores, a correção do eixo dos incisivos superiores para obtenção do paralelismo com o eixo facial, o avanço dos incisivos inferiores e a manutenção do perfil mole harmônico (Figura 10).
Verificadas as chaves de oclusão, segundo Andrews e Ricketts, seguiu-se análise dinâmica da oclusão por meio dos movimentos excursivos de protrusão e lateralidade direita e esquerda. Eliminados os contatos deletérios do lado de trabalho e não trabalho pelo ajuste oclusal, as desoclusões de lateralidade foram baseadas em desoclusão de guia canino sem interferência do lado de não trabalho e com os AFMPs equilibrados (Figura 11).

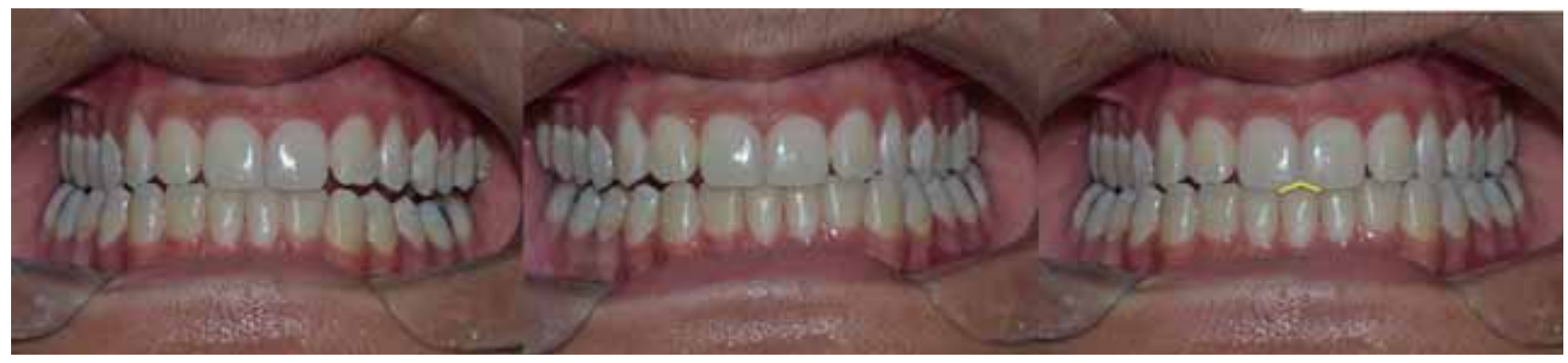

Figura 11 - AFMP equilibrados e edição das fotos anteriores evidenciando o equilíbrio dos AFMPs

\section{Caso clínico 3}

Paciente do sexo masculino, 15 anos, afrodescendente, dólico-facial, apresentando maloclusão de classe III, subdivisão direita de
Angle, mordida aberta anterior, interposição lingual durante a fonação e deglutição, apinhamento dos elementos 13, 15 e 23 e giroversão dos elementos 33 e 43 (Figura 12).

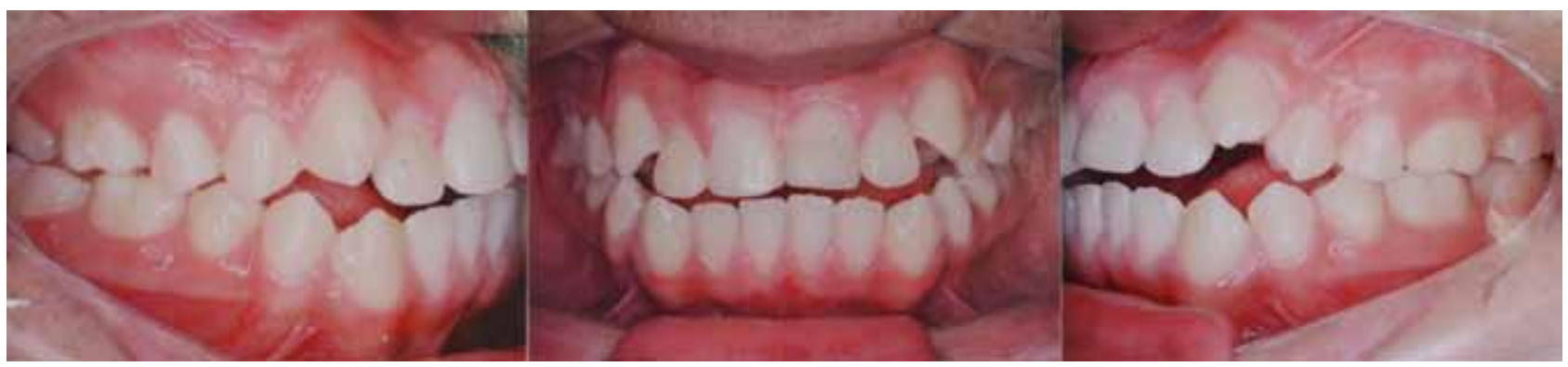

Figura 12 - Fotos intrabucais iniciais: nota-se a maloclusão de classe III, subdivisão direita e mordida aberta anterior
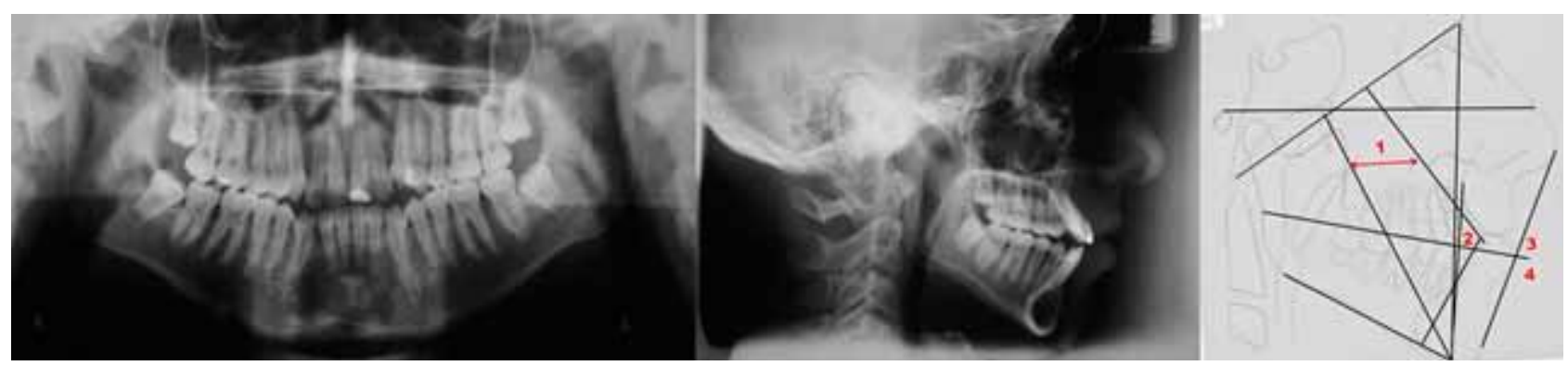

Figura13 - Radiografia panorâmica , telerradiografia e traçado cefalométrico inicial 
Ao analisar o traçado cefalométrico inicial, nota-se a divergência do eixo do incisivo superior com o eixo facial (Pt-Gn). A curva Spee encontra-se nivelada, sendo os incisivos superiores responsáveis pela mordida aberta; os incisivos inferiores apresentam-se protruídos em relação ao plano A-Po, um ângulo interincisivo menor que a norma recomendada para o tipo facial e um perfil mole harmônico com pequena contração do mento (Figura 13).

O paciente foi submetido a tratamento fonoaudiológico juntamente com a mecânica ortodôntica de correção da classe III subdivisão direita, fechamento da mordida pela extrusão dos incisivos anteriores e correção de sua angulação com o uso do arco base de Ricketts. Por meio dos arcos de alinhamento e nivelamento foram corrigidas as giroversões e desnivelamentos, finalizando, assim, a correção ortodôntica. Removido o aparelho corretivo, foi instalado um arco de Hawley para a contenção do arco superior e colada nos dentes inferiores uma barra de canino a canino com dobras para facilitar a higienização com fio dental. (Figura 14).

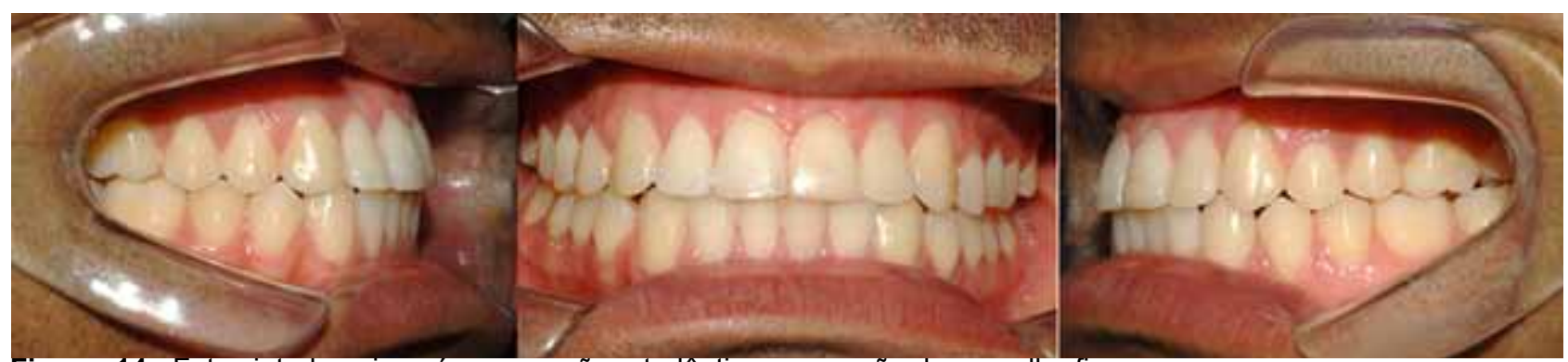

Figura. 14 - Fotos intrabucais após a correção ortodôntica e remoção do aparelho fixo
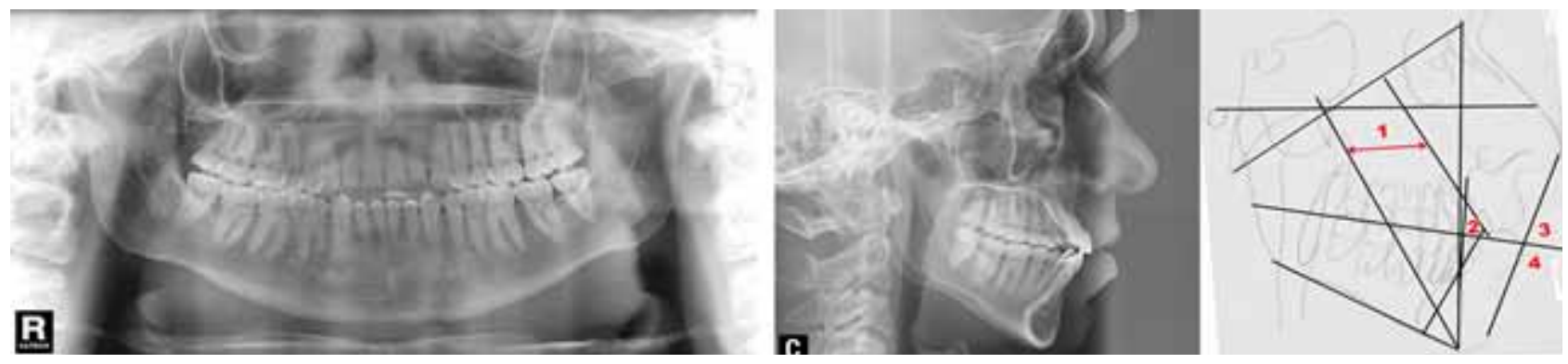

Figura 15 - Radiografia panorâmica telerradiografia e traçado cefalométrico final

Nota-se na radiografia panorâmica final a integridade óssea e das raízes, assim como o paralelismo entre elas e a presença dos terceiros molares com contato oclusal. O traçado cefalométrico final mostra que todas as mudanças propostas foram solucionadas: resolução da mordida aberta pela extrusão e correção da angulação dos incisivos superiores, correção da angulação dos incisivos inferiores, promovendo um ângulo interincisivo mais aberto, ideal para os tipos dólico-faciais, a correção do eixo dos incisivos superiores e o eixo facial e a manutenção da posição protruída dos incisivos inferiores em razão da característica genética da biprotrusão e devido à posição irregular da língua prétratamento ortodôntico, o perfil mole mantevese harmônico ainda com leve contração da região do mento (Figura 15).

Checadas as chaves de oclusão, segundo Andrews e Ricketts, seguiu-se análise dinâmica da oclusão por meio dos movimentos excursivos de protrusão e lateralidade direita e esquerda. Eliminados os contatos deletérios 
do lado de trabalho e não trabalho pelo ajuste oclusal, as desoclusões de lateralidade foram baseadas em desoclusão de guia canino sem interferência do lado de não trabalho e com os AFMPs equilibrados (Figura 16).

\section{Dıscussão}

Existem divergências na literatura quanto à oclusão estática ideal. Em 1972, Andrews ${ }^{3}$ idealizou as seis chaves da oclusão que deveriam ser cumpridas para uma oclusão ser considerada ideal: 1) relação molar; 2) angulação mesiodistal dos dentes; 3) inclinação vestíbulo-lingual dos dentes; 4) ausência de rotações dentais; 5) contato interproximal justo; 6) curva de Spee (ideal - plana ou moderada, máximo de 1,5 mm). Para Mulligan, ${ }^{4}$ equilíbrio oclusal éa "obtenção de contatos oclusais em que prevaleçam as resultantes de forças no sentido axial". Já Ricketts ${ }^{5}$ considera como sendo a primeira chave ideal o contato entre o segundo pré-molar superior e o primeiro molar inferior; a segunda é a posição vestíbulolingual do primeiro pré-molar inferior; a terceira é o ângulo interincisal e a relação "overbite/ overjet”, a quarta é a angulação dos caninos, a quinta são os segundos molares (a curva normal na oclusão inicia-se nos segundos molares) e a sexta é a forma do arco em harmonia com os músculos.

Os três casos descritos acima foram finalizados ortodonticamente seguindo todos os princípios descritos por Andrews $^{3}$ e Ricketts $^{5}$ em relação à oclusão estática ideal. $\mathrm{Na}$ fase de finalização também foi verificada detalhadamente a presença de contatos prematuros, que foram resolvidos com movimentações dentárias ou ajustes oclusais, evitando traumas oclusais. Este cuidado é fundamental, visto que o trauma oclusal pode ter consequências graves com o tempo. Segundo Consolaro, ${ }^{9}$ traumas oclusais, durante e depois do tratamento ortodôntico, em um primeiro momento, podem ser assintomáticos, com a presença de um discreto edema em razão da inflamação periodontal, podendo evoluir para perdas ósseas e, até mesmo, reabsorções dentárias importantes.

Uma oclusão estática ideal contribui muito para a estabilidade do tratamento ortodôntico, tendo em vista que as resultantes horizontais da força de oclusão geram tendência ao movimento, comprometendo a estabilização dentária e mandibular, devendo haver distribuição de contatos pelos planos inclinados dos dentes de forma que se anulem mutuamente. Da mesma forma, há necessidade de que se distribua a força da oclusão sobre todos os dentes posteriores para que haja contatos bilaterais simultâneos e equipotentes, evitando a sobrecarga em determinadas regiões ou desvios mandibulares que gerem esforços sobre poucos dentes. Desta maneira, o periodonto recebe estímulo fisiológico, produzindo fibras colágenas e mantendo a espessura das trabéculas ósseas no osso alveolar. ${ }^{10}$ No entanto, não somente a oclusão estática é suficiente para o adequado funcionamento do sistema estomatognático; a verificação da dinâmica oclusal obtida

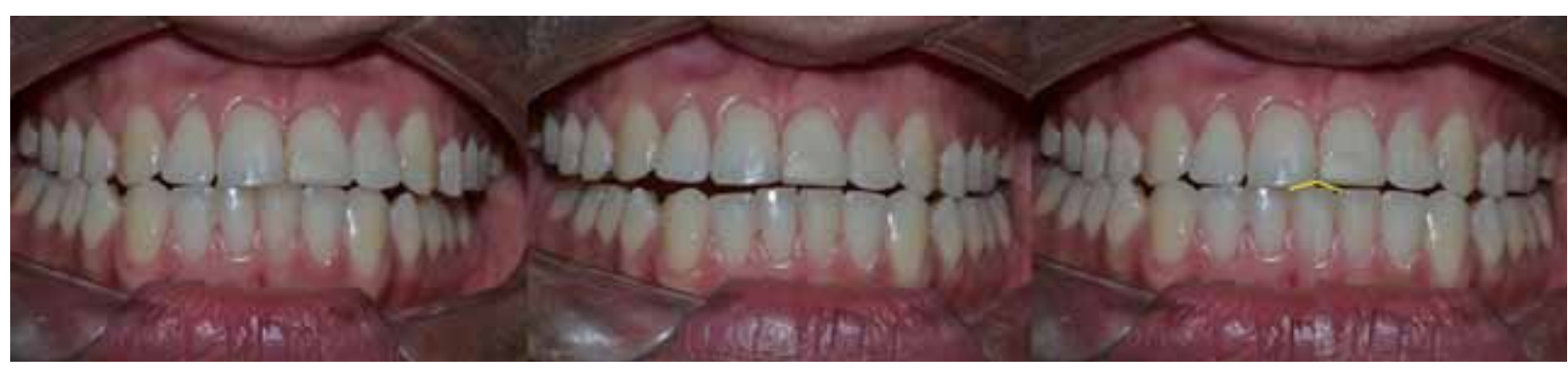

Figura 16 - AFMPs equilibrados e edição das fotos anteriores evidenciando o equilíbrio dos AFMPs 
mediante os movimentos mandibulares e o estabelecimento de uma função normal e equilibrada são imprescindíveis para uma oclusão fisiologicamente adequada.

Portanto, ao avaliar a oclusão dinâmica, devem ser verificados todos os contatos dentais ocorridos durante os movimentos mandibulares, ou seja, a oclusão mutuamente protegida na qual, durante a protrusão e lateralidade, os dentes posteriores (durante a protrusão) e o lado de não trabalho (na lateralidade) ficam livres de contato. ${ }^{11,12,13,14}$ Pequenas divergências quanto à guia em caninos ${ }^{11,13,14}$ ou em grupo ${ }^{12,13,14}$ são encontradas na literatura.

A mastigação ideal do ser humano é realizada bilateralmente, com movimentos rotatórios e com os lábios selados. Este padrão de mastigação possibilita a distribuição das forças mastigatórias, intercala trabalho e repouso, promove a sincronia, equilíbrio muscular e funcional, estimula o desenvolvimento e/ou manutenção dos arcos dentários e a estabilidade oclusal. ${ }^{15,16}$

Apesar de autores como Pond et al. ${ }^{17}$ relatarem que os fatores periféricos (oclusais e articulares) teriam influência sobre o padrão mastigatório apenas durante a fase em que este está sendo estabelecido, a grande maioria de pesquisadores ${ }^{18,19,20,21,22,23,24}$ afirma ser a mastigação controlada por estes fatores, independentemente da idade. Sendo assim, parece pertinente afirmar que somente uma oclusão ideal estática e dinâmica seria capaz de possibilitar a ocorrência de mastigação bilateral alternada, o que foi obtido nos casos clínicos relatados.

A mastigação bilateral alternada, além contribuir para a manutenção do equilíbrio oclusal, com excursões amplas e contatos oclusais fisiológicos, atividade muscular bilateralmente sincrônica e força uniforme sobre os tecidos de suporte dos dentes, fornece estímulos adequados para o desenvolvimento normal, sagital e transversal da mandíbula e da maxila e participa, direta e indiretamente, na prevenção dos problemas periodontais e das disfunções temporomandibulares. ${ }^{25}$

A mastigação unilateral, por sua vez, é o padrão de mastigação em que se observa que a trituração e a pulverização do alimento ocorrem exclusiva ou predominantemente em um dos lados da cavidade oral. Neste padrão, ocorre estímulo inadequado do crescimento dentofacial; maior desenvolvimento da mandíbula do lado de não trabalho e maior desenvolvimento da maxila do lado de trabalho, ${ }^{26,27}$ o que resulta em danos esqueléticos, musculares e de posicionamento dentário, prejudicando o equilíbrio do sistema estomatognático.

Uma das formas de verificar a presença de mastigação unilateral baseada em uma análise oclusal foi descrita por Planas, ${ }^{8}$ em 1980, quando relatou o AFMP. Segundo o autor, se os AFMPs direito e esquerdo forem diferentes, a mastigação tende a tornar-se unilateral e, preferencialmente, do lado com AFMP menor, comprometendo a estabilidade da correção da maloclusão no longo prazo. Esta afirmação foi confirmada em um estudo clínico por Pignataro Neto, ${ }^{28}$ que identificou uma correlação significante entre o lado de preferência mastigatória com o lado onde o AFMP é menor.

Os casos descritos acima apresentaram, após a correção ortodôntica, a presença de AFMPs diferentes. Acreditando serem os fatores oclusais determinantes para - estabelecimento de uma mastigação adequada, ou seja, bilateral alternada, ajustes oclusais foram realizados após o tratamento ortodôntico.

No caso 1, ficaram as diferenças ao chegar o movimento de lateralidade direita e esquerda e, após ajustes oclusais por desgaste seletivo precisos na região de caninos com a finalidade de estabelecer um equilíbrio entre o AFMP 
direito e esquerdo, estas diferenças são eliminadas levando ao equilíbrio dos AFMPs. Já nos casos 2 e 3, somente é evidenciado o equilíbrio dos AFMPs, porém este equilíbrio também foi obtido por meio de ajuste oclusal por desgaste seletivo.

A alteração do padrão mastigatório pela manipulação de fatores oclusais foi inicialmente descrita por Planas $^{8}$ utilizando desgastes seletivos, pistas diretas e indiretas, criando condições proprioceptoras para o restabelecimento da mastigação bilateral alternada. Autores como Mandetta ${ }^{29}$, Mantibeller ${ }^{22}$ e Simões ${ }^{23}$ obtiveram resultados igualmente eficazes com a mesma técnica.

Fica evidente que os desgastes realizados nos casos clínicos, após a finalização ortodôntica, buscando uma oclusão ideal dinâmica e estática, são fundamentais para o restabelecimento de uma mastigação adequada, o que certamente garantirá sua estabilidade futura.

Uma análise oclusal criteriosa deve fazer parte do tratamento ortodôntico, ou seja, o paciente somente deverá receber alta do tratamento ortodôntico depois de devolvida a oclusão normal, estática e dinâmica.

\section{Conclusão}

Após a finalização do tratamento ortodôntico, é coerente verificar, não somente as chaves estáticas de finalização ortodôntica, mas também a oclusão dinâmica (lateralidade e protrusão). Deve-se fazer análise do padrão oclusal, do equilíbrio dentário e da necessidade de ajustes oclusais por desgaste seletivo ou acréscimo por materiais restauradores que podem ser indicados para um refinamento dos contatos oclusais para o desejado equilíbrio e estabilização da posição mandibular. Os ajustes oclusais, após tratamento ortodôntico, melhoraram a estabilidade oclusal e funcional, proporcionando um equilíbrio dentário e permitindo aos pacientes uma mastigação bilateral.

\section{REFERÊNCIAS}

1 Monnerat C, Mucha JN. Ortodontia - oclusão estabilidade. Rev Dental Press Ortodon Ortop Facial. 2000; 5(1): 32-44.

2 Angle, EH. Tretament of maloclusion of the teeth. 7th ed. Philadelphia: S. S. Withe; 1907. p. 628.

3 Andrews LF. The six keys to normal occlusion. Am J Orthod. 1972; 62(3): 296-309.

4 Mulligan TF. Common sense mechanic: static equilibrium. J. Clin. Orthod. 1979 Nov.; 13(11): 762-6.

5 Ricketts, RM. Consummate occlusion. California: American Institute for Bioprogressive Education. 1996. p. 39-48.

6 Silva APP; Vitalino RAB; Marntinez M; Chiappetta ALML. Correlation between corporal posture and chewing after transitory dentition. Rev CEFAC. 2004 Out.; 6(4): 363-9.

7 Tompson, J.R. Function. The neglected phase of orthodontic. Angle Orthod. 1956 Jul.: 26(3): 129-43.

8 Planas P. L'Angle Funtionel Masticatoire Planas (AFMP). L'Orthodontie Française, 1980; 51: 171-8.

9 Consolaro A. Trauma oclusal antes, durante e depois do tratamento ortodôntico: aspectos morfológicos de sua manifestação R Dental Press Ortodon Ortop Facial. nov.-dez. 2008; 13(6): 20-3.

10 Okeson JP. Critérios para uma oclusão funcional ideal. In: Okeson JP. Tratamento das desordens temporomandibulares e oclusão. 4a ed. São Paulo: Artes Médicas; 2000.

11 Roth RH. The maintenance system and occlusal dynamics. Dent Clin North Am. 1976; 20: 761-88.

12 Beyron H. Optimal occlusion. Dent Clin North Am. 1969 Jul.; 13(3): 537-54.

13 Mohl ND, ZARB GA, Carlsson GE, RUGH JD. Fundamentos de oclusão. 2a ed. Rio de Janeiro: Quintessence; 1991.

14 Ramfjord SP, Ash MM. Oclusão. 3a ed. Vieira DF, tradutor. Rio de Janeiro: Interamericana; 1984.

15 Cattoni DM. Alteração da mastigação e deglutição. In Ferreira LP, Befi-Lopes DM, Limongi 
SCO, organizadores. Tratado de fonoaudiologia. São Paulo: Roca; 2004. 277-284.

16 Douglas CR. Patofisiologia oral. São Paulo: Pancaster; 1998.

17 Pond, LH., Barghi, N., Barnwell, G.M. Occlusion and chewing side $\mathrm{p} \mathrm{refere} \mathrm{n} \mathrm{ce}$. J. Prosthet Dent. 1986 Apr.; 55(4): 498-500.

18 Hildebrand GY. Studies in the mastigatory moviments of the lower jaw. Scand Arch Phisyol. 1931, Jan.; (Supl. 61).

19 Jankelson B, Hoffman GM, Hendron JA Jr. The physiology of the stomatognathic system. J Am Dent Assoe. 1953; 47: 463-75.

20 Ahlgren J. Mechanism of mastication. Acta Odontol. Scand. 1966; (Supl.44): 24.

21 Hoogmartens MJ, Caubergh M.A. Chewing side preference during the first chewing cycle as a new type of lateral preference in man. Electromyogr Clin Neurophysiol. 1987 Feb.; 27(1): 3-6.

22 Montibeller RR. Ajuste oclusal por desgaste seletivo no tratamento das disfunções temporomandibulares. [tese], Piracicaba: Faculdade de Odontologia de Piracicaba, Universidade Estadual de Campinas; 1998.

23 Simões WA. Visão do crescimento mandibular e maxilar. J B O. mai.-jun. 1998; 3(15): 9-18.

24 Scarla TTI. A. Paralelas funcionais e ângulo crânio-escapular: novos métodos de diagnósti- co para disfunção do sistema estomatognático. J B O. mar.-abr. 1998; 3(14).

25 Monnerat C, Mucha JN. A oclusão funcional ideal e a estabilidade do tratamento ortodôntico: uma revisão. Ortodontia Gaúcha. jul.-dez. 1998; 2(2): 116-26.

26 Amaral DB. Mastigação unilateral x oclusão normal: um estudo sobre sua ocorrência em crianças de 4 a 5 anos. Rev CEFAC. 2000; 2(2): 23-30.

27 Christensen LV, Radue JT. Lateral preference in mastication: An electromyographic study. J Oral Rehabil. 1985; Set; 12(5): 429-34.

28 Pignataro Neto G. Análise da correlação entre os ângulos funcionais mastigatórios direito e esquerdo com o lado de preferência mastigatória. [dissertação]. Piracicaba: Faculdade de Odontologia de Piracicaba, Universidade Estadual de Campinas; 2000.

29 Mandetta S. Causas da mastigação unilateral e importância do ajuste oclusal das guias laterais na sua correção. Revista Paul Odont. jan.-fev. 1994; 1.

Submetido em: 4-12-2014

Aceito em: 3-6-2015 